\title{
SURGICAL TREATMENT OF HYDRONEPHROSIS IN PARAPLEGIA
}

\author{
By J. Cosbie Ross \\ Liverpool Regional Paraplegic Centre
}

INTRODUCTION

IT is a fact that, in the past, attention from the urological point of view has been concentrated on the bladder and on micturition as this presented the immediate and pressing problem. It is only with the passing years and the careful follow-up studies of Talbot and Bunts (1949), of Hutch and Bunts (195I) and of Damanski and Gibbon (1956) that it has been generally acknowledged that the long-term prognosis rests on the preservation of renal function. As a direct result it has not been realised that the development of hydronephrosis may constitute a formidable problem. It is a necessary to point out that renal failure may develop in a paraplegic patient without any evidence of hydronephrosis whatsoever.

Hydronephrosis was found to be present in more than a third of the group of patients kept under review for a number of years by Damanski and Gibbon (1956), developing as early as two months or as late as eight and a half years after injury.

Hydronephrosis in traumatic paraplegia is due to three factors which may vary considerably in relative importance. These three factors are:
I. Neural damage.
2. Urinary infection.
3. Back-pressure.

Again, it must always be remembered that hydronephrosis may develop without obvious cause and that spontaneous recoveries may take place. A study of these patients emphasises the marked lability of the upper urinary tract in the paraplegic. In other words hydronephrosis may be reversible.

Again, hydronephrosis is important, not only on account of the possibility of progressive renal failure, but also because it has been established that a moderate degree of dilatation of the ureters and kidneys seems to be sufficient to prevent more than a temporary sterilisation of the urine in spite of antibiotics (Cosbie Ross, Damanski \& Gibbon, 1957). In discussing the treatment of hydronephrosis it is necessary also to deal with hydro-ureter and, to a certain extent, with ureteric reflux, as these conditions are often found together and are due to a common aetiology. Warning signs of an impending hydronephrosis are deterioration of bladder function, hypertonia, trabeculation and ureteric reflux (Cosbie Ross, 1960).

The treatment of hydronephrosis due to impaction of calculi has been omitted as standard methods are available under such circumstances.

\section{TREATMENT}

For practical purposes the treatment of hydronephrosis in the paraplegic may be expressed thus:

I. Prophylactic measures.

2. Neurosurgical measures.

3. Measures designed to eliminate urinary infection and back-pressure. 
4. Plastic operations on the ureter and ureterovesical orifice.

5. Permanent catheter or suprapubic drainage.

6. Permanent diversion of the urine by $\left\{\begin{array}{l}\text { Ureterostomy. } \\ \text { Ileal loop bladder. }\end{array}\right.$

I. Prophylactic Measures. It is probable that with the earlier admission of patients with traumatic paraplegia to special centres, with increasing knowledge and more skilful management of the initial stages of treatment, the incidence of hydronephrosis will diminish in the future (Damanski, 196I). At the same time it must be pointed out that hydronephrosis may develop years after the injury so that prophylactic measures necessarily include a careful follow-up at yearly or halfyearly intervals for the rest of the patient's life. The initial methods used at the Liverpool Regional Centre to combat the onset of infection are as follows:

I. Forced diuresis.

2. Continuous urethral drainage using a Gibbon catheter.

3. Early ambulation.

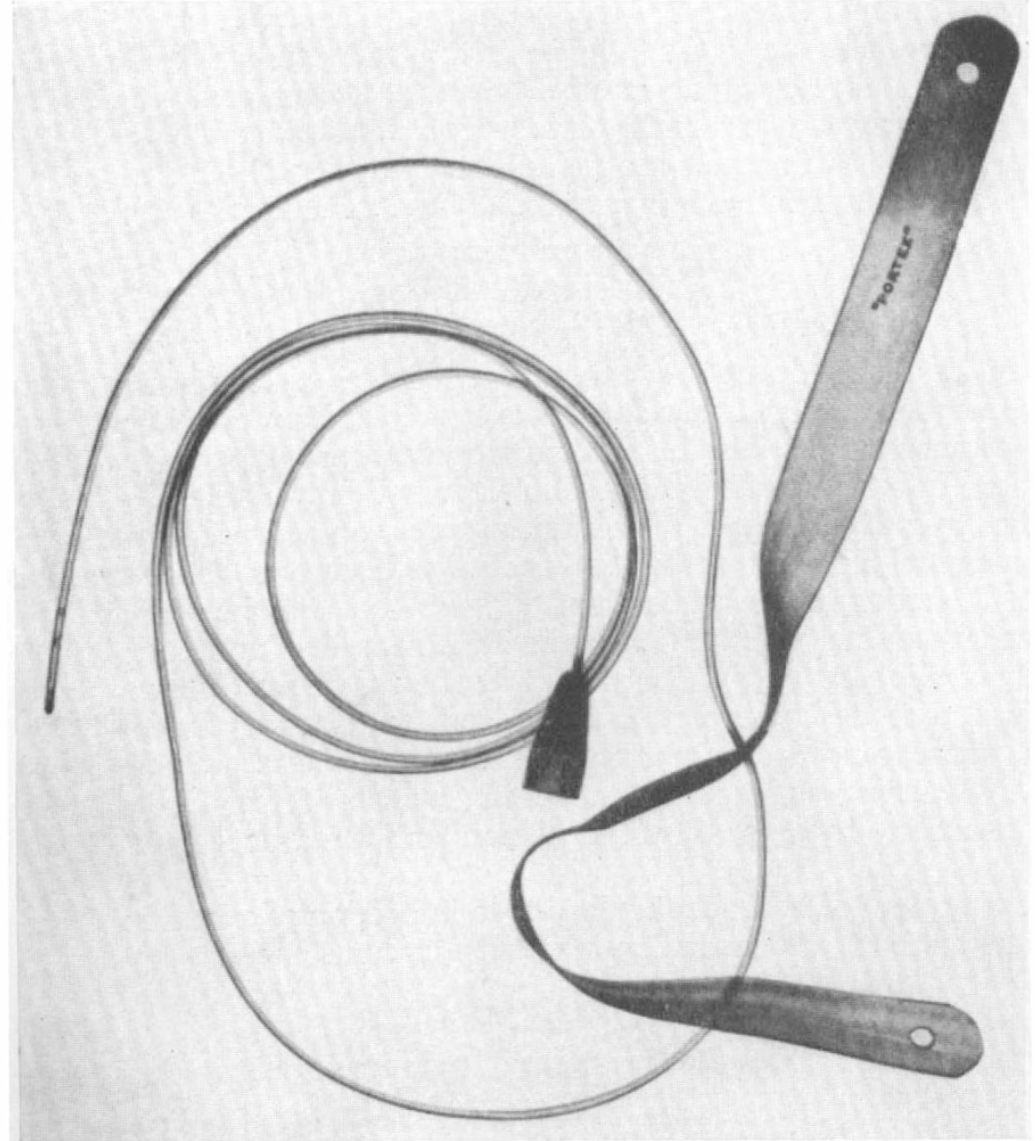

FIG. I

Gibbon polythene catheter. 
Throughout the period of treatment (and in fact for the rest of the patient's life) a large intake of fluids, approximately six pints a day is essential. Urinary antiseptics, especially antibiotics, are given only in short courses when specifically indicated by an exacerbation of urinary infection. Chemotherapy should not be given continuously except in small dosage in chronic pyelonephrit is.

The catheter designed by Gibbon, is shown in Figures I and 2. This catheter, which is extremely light and non-irritant to the urethra, forms a completely enclosed drainage system which need not be changed or interfered with for four days at a time and sometimes for weeks if necessary.

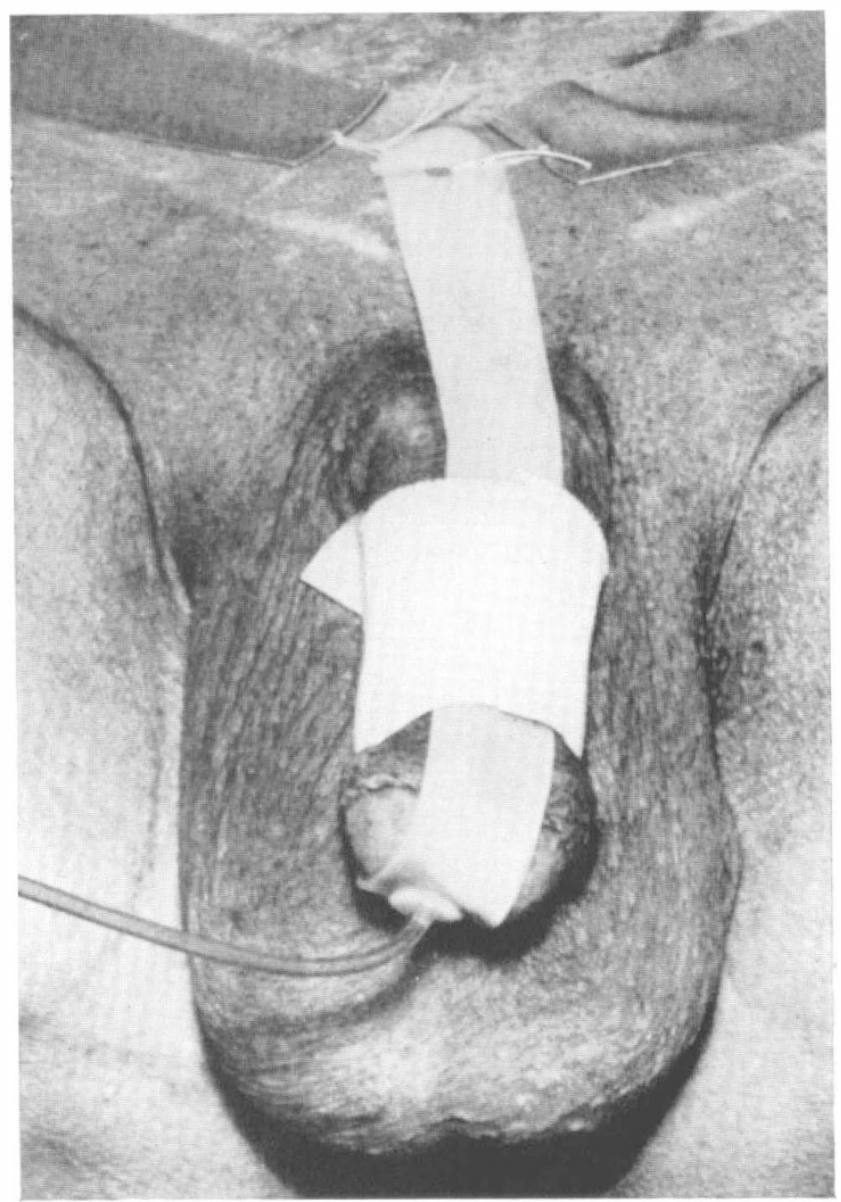

FIG. 2

Fine polythene catheter in use (Gibbon).

Prophylaxis as far as back-pressure is concerned depends upon preventing the patient being left with a blocked catheter or, later in the course of treatment, with an automatic bladder complicated by a large residual urine. 
2. Neurosurgical Measures. The degree of neural damage is obviously of great importance. In partial lesions the development of hydronephrosis is less likely. For example, in extention injuries of the cervical spine the complication is rarely seen.

It is well known that the elimination or the reduction of spasticity of the skeletal muscles may have a favourable effect both on residual urine and hydronephrosis. At the Liverpool Centre, LI to SI anterior rhizotomy is performed in complete neurological lesions, but when the neural damage is incomplete treatment is limited to tenotomies of the iliopsoas and hamstrings, elongation of the Achilles tendon or gastrocnemius slide.

An example of this form of treatment is shown in Figure 3. This patient had a fracture-dislocation of $\mathrm{T}_{5}$ on T6, and in 1954 the I.V.P. was normal (fig. $3 a$ ). However, the I.V.P. carried out in 1955 showed bilateral hydronephrosis (fig. $3 b$ ). In 1957 a subarachnoid alcohol block was carried out for spasticity of the legs and an I.V.P. carried out some months after the alcohol block showed an almost normal appearance of the upper urinary tract (fig. $3 c$ and $d$ ).

Hutch (1957) believes that the numerous, powerful and erratic impulses arising in the distal stump of the spinal cord are fundamentally responsible because they cause the bladder to become contracted and trabeculated, resulting in sacculation of the bladder wall at the site of the intramural ureter. As a result of these two factors, i.e. small capacity spastic bladder and sacculation, hydro-ureter and hydronephrosis develop. Therefore Hutch advises sacral rhizotomy of the 2nd, 3 rd and 4th sacral nerves (both anterior and posterior roots) and has shown an increase in bladder capacity and a diminution of hydronephrosis; in some complete lesions the distal stump of the cord was removed. At the Liverpool centre there has been a reluctance to undertake such drastic neural procedures, eliminating as it does the entire reflex arc controlling micturition.

3. Measures designed to eliminate Urinary Infection and Backpressure. There is much evidence that the development of hydronephrosis is frequently due to some form of obstruction at the bladder-neck or at the external sphincter level. In support of this must be mentioned:

I. Hydronephrosis is frequently bilateral.

2. The high incidence of hypertonia and trabeculation of the bladder.

3. The frequent incidence of a high residual urine.

The importance of this aspect is also emphasised by the fact that the incidence of hydronephrosis is only 20 per cent. in incomplete lesions, presumably because the great majority of incomplete lesions recover satisfactory bladder emptying at a comparatively early stage.

For this reason it has been the writer's policy to make every effort to eliminate residual urine in all patients. Methods available for ensuring efficient bladder voiding include the following:

I. Intrathecal alcohol block.

2. Resection of the bladder-neck.

3. Pudendal neurectomy.

4. Division of the external sphincter. 


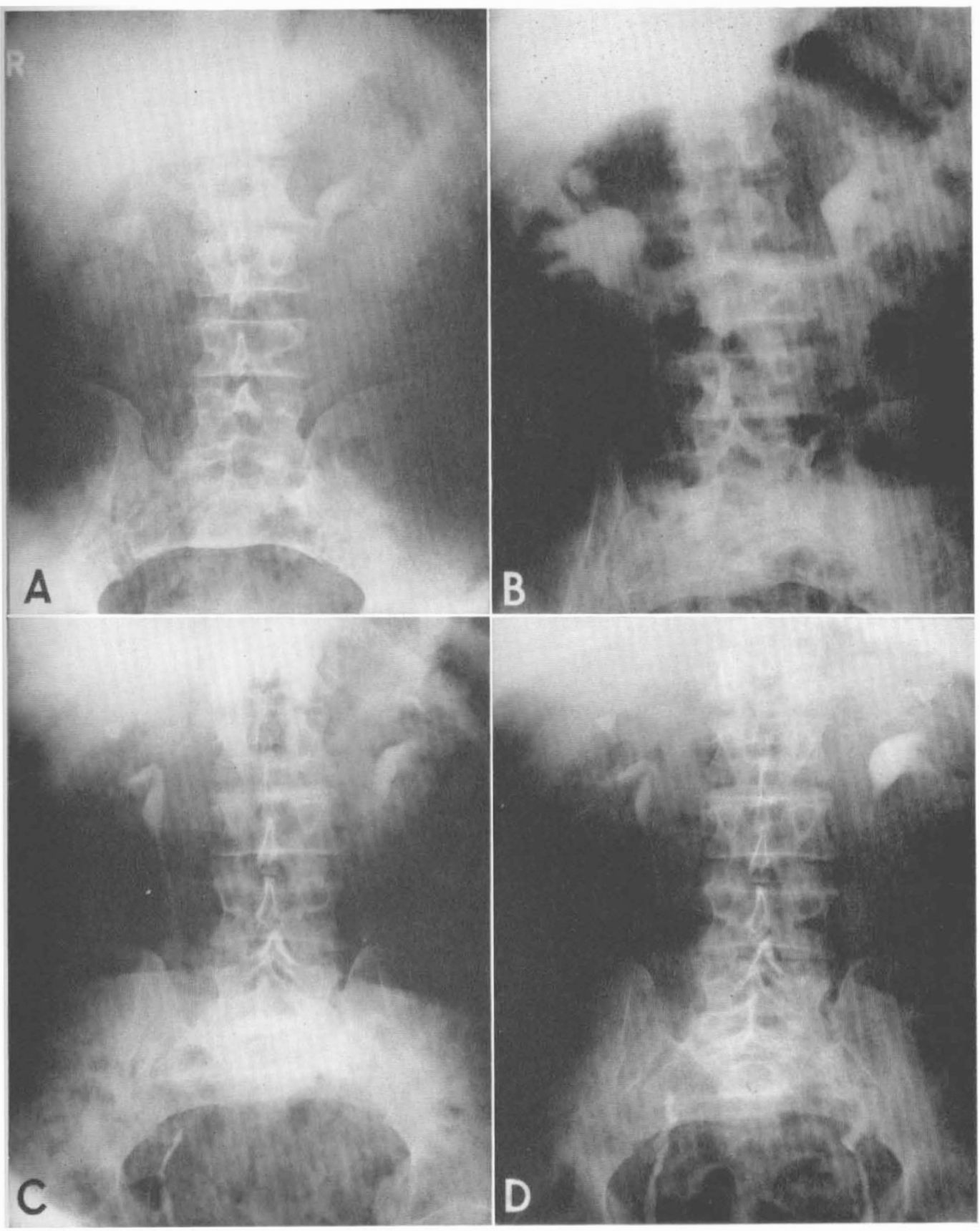

FIG. 3

(a) Normal I.V.P. (1954). (b) Bilateral hydronephrosis (1955). (c) Normal I.V.P. some months after subarachnoid alcohol block (1957). (d) Recent normal I.V.P. 


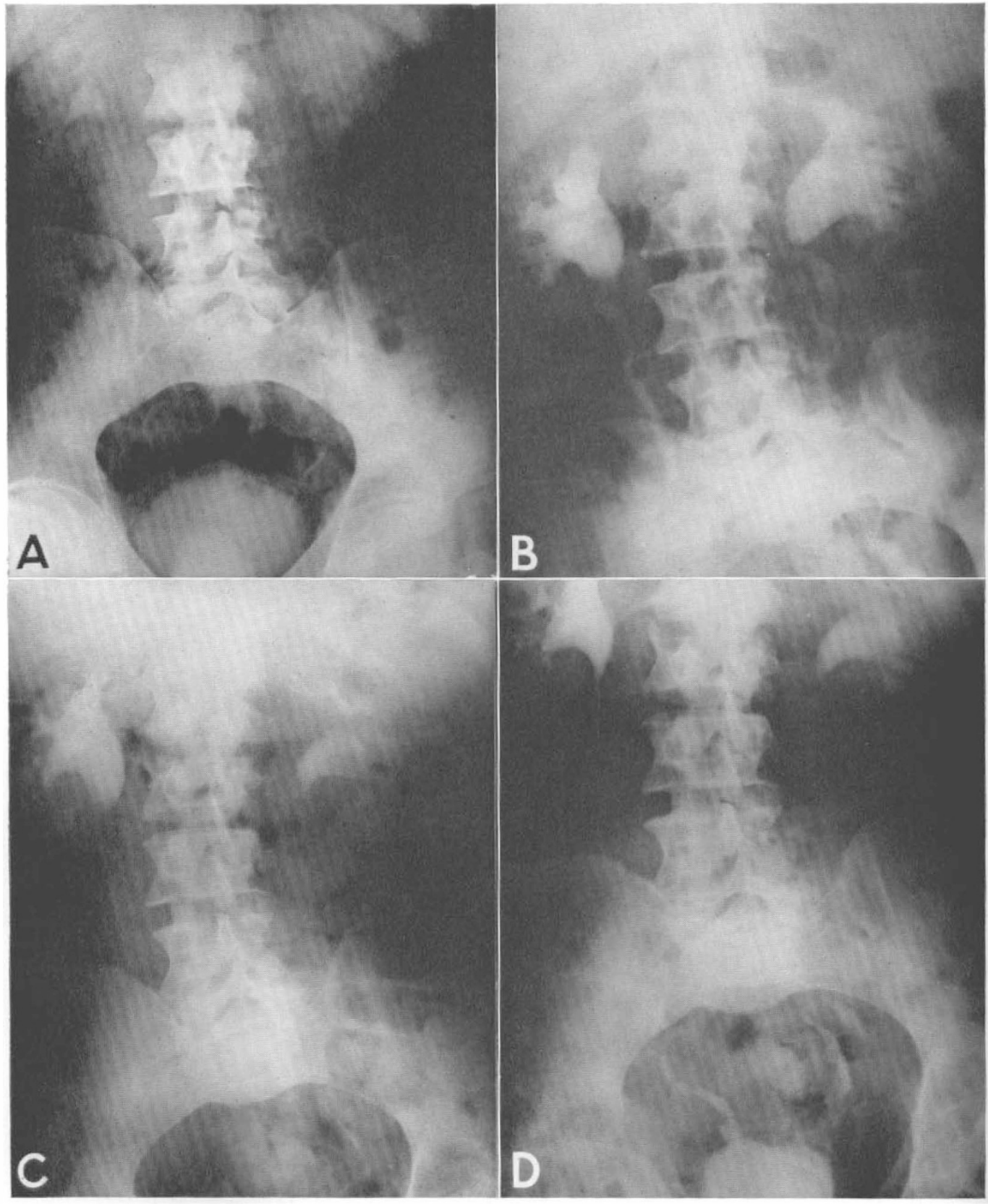

FIG. 4

(a) Normal I.V.P. (1953). (b) Dilatation of the upper urinary tract (1954). (c) Improvement of the I.V.P. following bladder-neck resection (I955). (d) A further improvement. 
Patient H. H. sustained a fracture dislocation of T8 on T9. He was discharged home in 1952 with a residual urine of 6 ounces. In I953 the I.V.P. was normal (fig. 4). At his follow-up examination in I954, there was a considerable degree of dilatation of the upper urinary tract (fig. $4 b$ ). A bladder-neck resection was performed in 1955. In I955 the I.V.P. showed considerable improvement and a further improvement had occurred in 1959 (figs. $4 c$ and $d$ ).

The dramatic benefit both in appearance and function after division of the external urethral sphincter is shown in Figures $5 a$ and $b$.

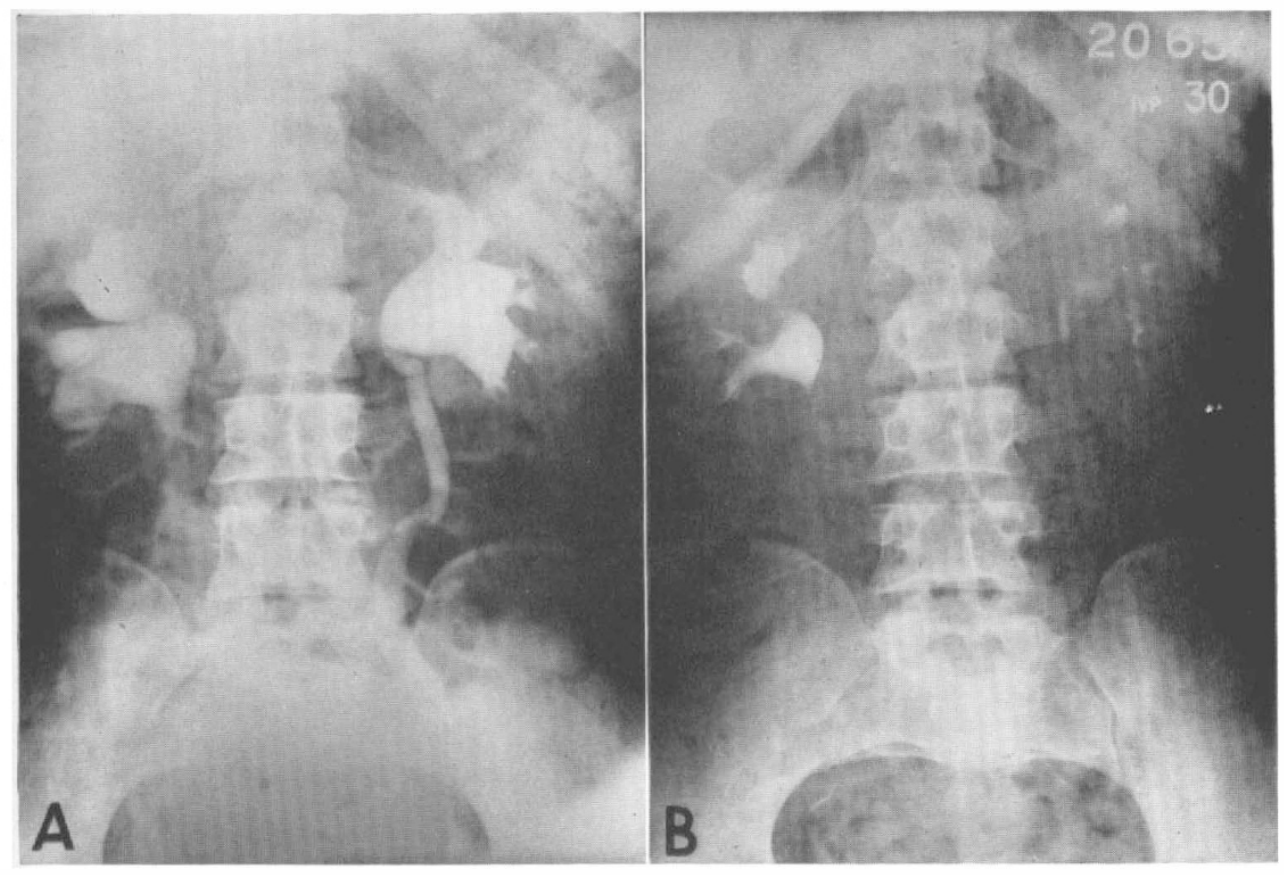

FIG. 5

(a) Gross dilatation of the upper urinary tract (1956). (b) Considerable improvement of the I.V.P. following division of the external sphincter.

Another patient had a normal I.V.P. early in I954 (fig. 6a) whereas later in that year a marked hydronephrosis was accompanied by a large residual urine (fig. 6b). However, following bilateral pudendal neurectomy a considerable improvement was demonstrated (fig. 6 c). Using these methods it has been possible to achieve a demonstrable improvement in the hydronephrosis in 13 patients out of a total of 39. It is hoped, also, that in some of the others the progress of the hydronephrosis has been arrested but a further period of follow-up investigation is necessary before this point can be established.

4. Plastic Operations on the Ureter and Ureterovesical Orifice. It is a general experience that paraplegic patients with hydronephrosis have not proved suitable for the various plastic operations carried out on the renal pelvis for hydronephrosis in individuals without neural damage. Apart from other factors the 

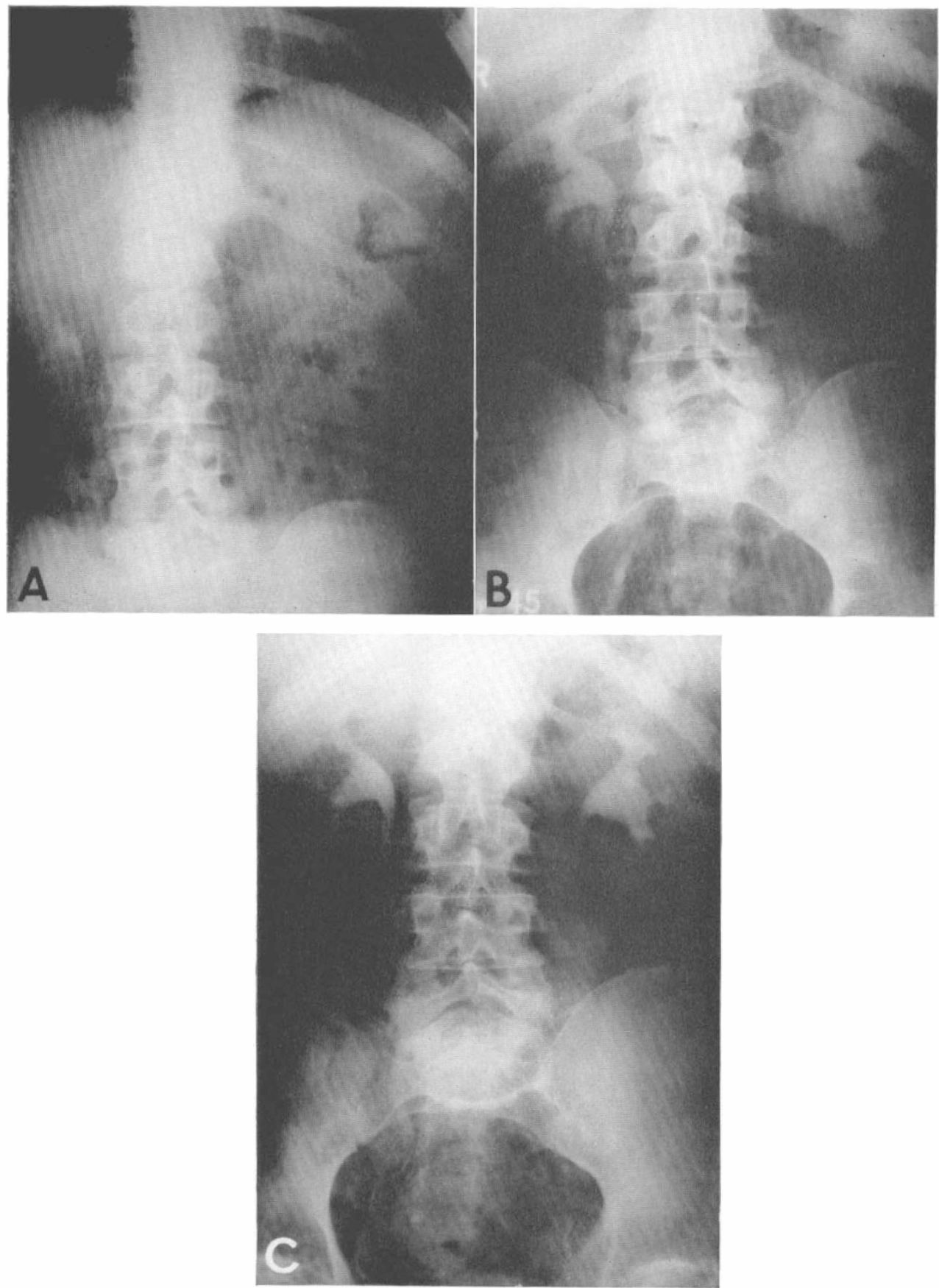

FIG. 6

(a) Normal I.V.P. (1954). (b) Marked hydronephrosis and large residual urine (late 1954). (c) Considerable improvement in the I.V.P. following pudendal neurectomy (1958). 
hydronephrosis in paraplegia is often of the renal or calyceal type, with an intrarenal pelvis. Moreover, if it is agreed that the changes in the upper tracts are secondary to those in the bladder, plastic procedures on the pelvi-ureteric junction are valueless in this condition. On the other hand, hydronephrosis may be benefited by a plastic operation carried out on the lower end of the ureter for ureteric reflux. In a previous communication it has been pointed out that the frequent association between hydronephrosis and reflux suggests a common cause.

Hydronephrosis and Reflux (Ross, J. Cosbie et al. 1960)

$$
\begin{aligned}
& \text { Bilateral hydronephrosis }\left\{\begin{array}{l}
\text { Bilateral reflux }-4 \\
\text { Unilateral reflux-6i }
\end{array}\right. \text { io } \\
& \text { Unilateral hydronephrosis }\left\{\begin{array}{l}
\text { Ipsilateral reflux-4 } \\
\text { Bilateral reflux }-3
\end{array}\right\} 7
\end{aligned}
$$

Further, the degree of hydronephrosis frequently corresponds with the grade of reflux observed.

Hutch (I955) has pointed out the frequency of a saccule, the so-called 'dogear', and of a narrow segment at the lower end of the dilated ureter. He considers that this narrow zone represents the intramural part of the ureter displaced so as to lie outside the bladder wall. In this position it may obstruct the flow of urine by its lack of peristalsis or by kinking, and so promote hydronephrosis with or without regurgitation. The writer has found no difficulty in passing a ureteric catheter in these cases and this is in accordance with Hutch's view that this is a functional and not an organic obstruction.

Some patients have shown these special features and the writer has, on several occasions, carried out Hutch's operation, but the long-term results have proved somewhat disappointing. Figure 7 illustrates the steps of the operation.

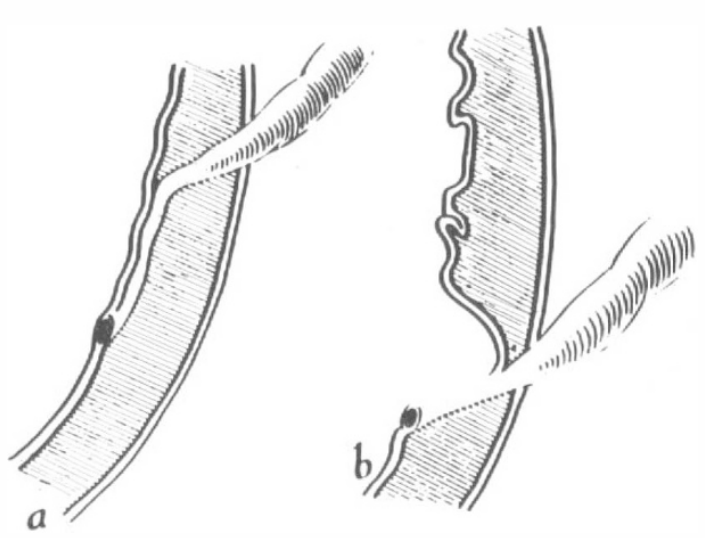

FIG. 7

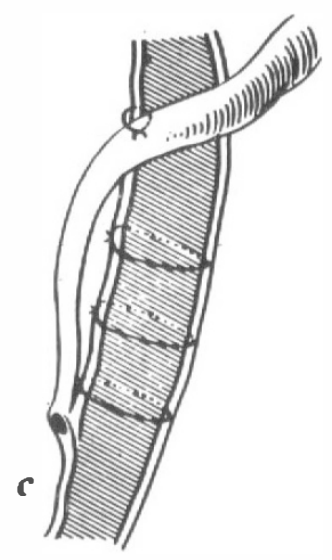

(a) The sagittal plane of the normal ureter as it passes through the bladder wall.

(b) The changes at the ureterovesical junction that cause the dog-ear seen on the cystogram, and the saccule seen cystoscopically. (c) The postoperative situation achieved with the ureterovesical plastic operation. (After Hutch.) 
5. Permanent Suprapubic Drainage. In connection with this procedure, which should be regarded as a last resort, a warning must be included. To illustrate this the writer had under his care a patient who had a spinal accident during the war in 1943, and at that time a suprapubic cystostomy was carried out and continued until he was admitted to the Liverpool Regional Centre many years later.

On admission the intravenous pyelogram showed a normal upper urinary tract. The suprapubic fistula was closed but a subsequent intravenous pyelogram showed marked hydronephrosis with bilateral backflow. Bors (I957) has also pointed out the danger of closing a long-established suprapubic fistula and the development of hydronephrosis following such an action. On the other hand, provided a cysto-urethrogram shows a satisfactory state of the bladder-neck and also excludes a hold-up at the external sphincter level, it may be safe to close a suprapubic fistula of many years standing.

\section{Diversion of the Urine by $\left\{\begin{array}{l}\text { Ureterostomy } \\ \text { an ileal bladder }\end{array}\right.$}

With increasing knowledge of paraplegia and the greater efficiency of its treatment, diversion of the urine is becoming less necessary and is only now performed in the exceptional case. Occasionally, hydronephrosis and renal deterioration progress in spite of all efforts to achieve efficient bladder voiding. In such a case (especially if complicated by gross infection), it is obvious that diversion of the urine is a life-saving operation. Similarly, in the patient with an intractable obstruction at the external sphincter level it is not safe or wise to attempt division of the external sphincter if there is advanced hydronephrosis. Figure 8 shows diversion by means of a bilateral nipple or 'spout' ureterostomy, but recently it has been shown that the operation may be performed in such a way that one orifice (or a double-barrelled orifice) drains into one receptable (Lapides, 1962). On the other hand, the ureters may be implanted into a segregated loof of ileum (fig. 9).

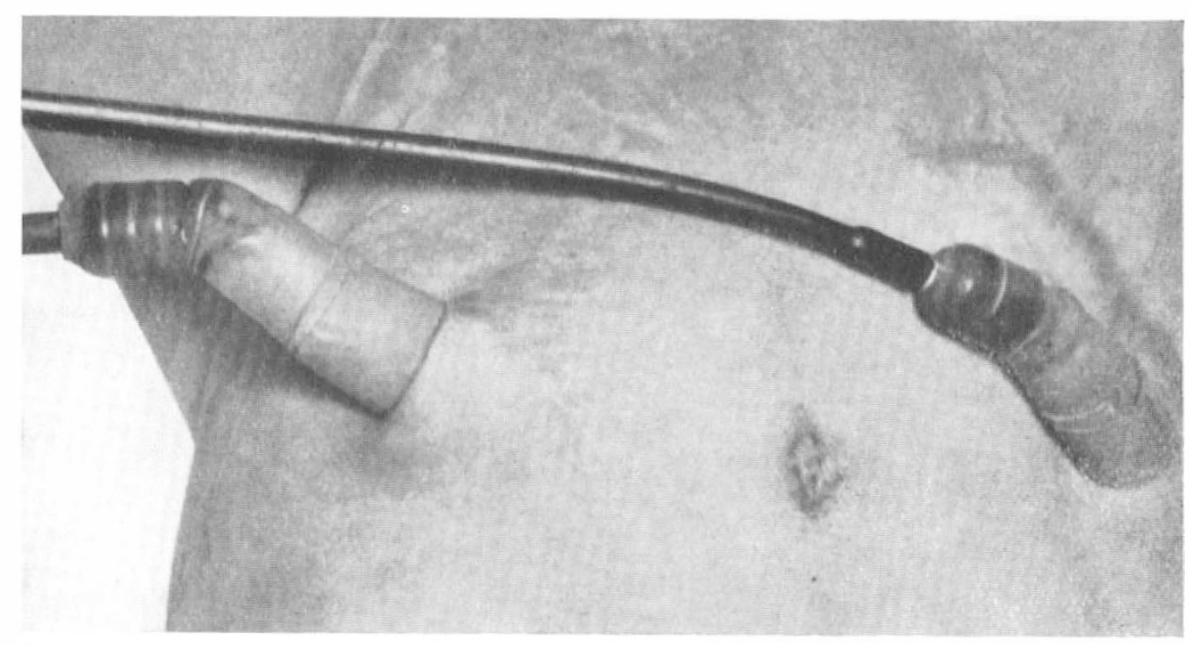

FIG. 8

The Bilateral nipple or 'spout' ureterostomy. 

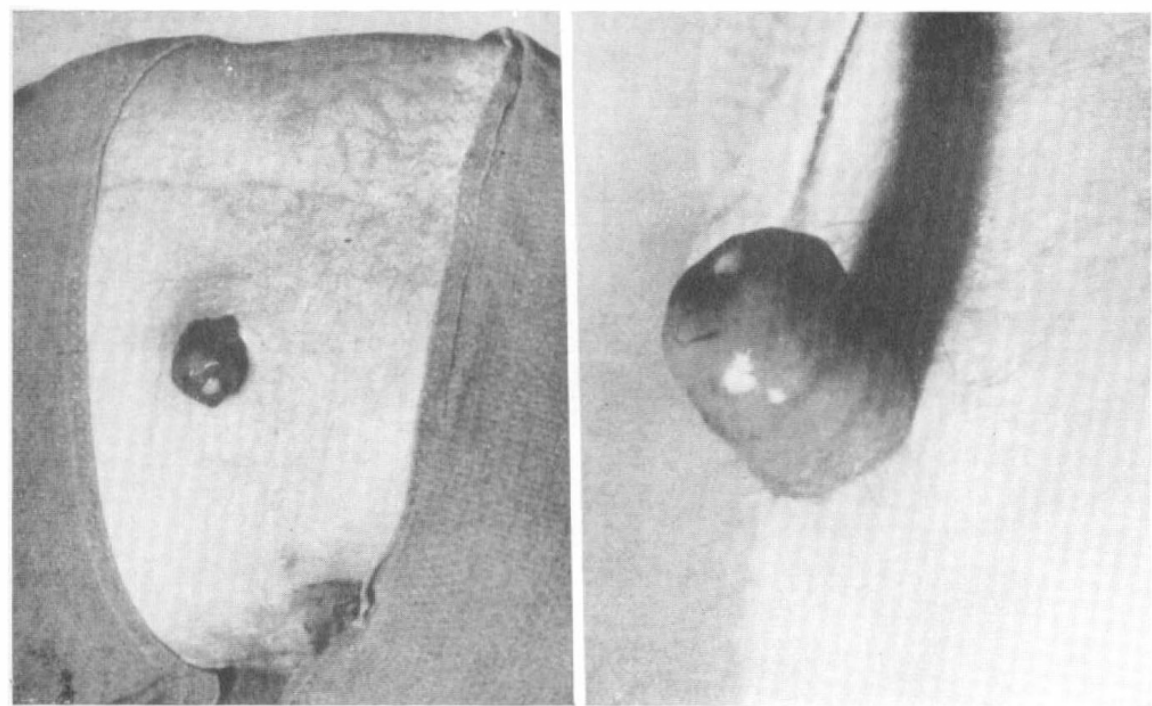

FIG. 9

Implantation of the ureters into a segregated ileal loop.

\section{SUMMARY}

I. Hydronephrosis developed in more than a third of paraplegic patients kept under review for a number of years.

2. It is a serious complication if progressive and threatening renal function.

3. Modern methods applied during the period immediately after the injury may diminish the subsequent incidence of hydronephrosis.

4. Hydronephrosis is frequently eliminated if efficient bladder voiding is achieved by means of resection of the bladder-neck or division of the external sphincter (Cosbie Ross, Damanski \& Gibbon, 1957).

\section{RÉSUMÉ}

I. L'hydronéphrose s'est developée chez plus du tiers des nos paraplégiques suivis pendant plusieures années.

2. C'est une complication sérieuse si elle est d'évolution progressive, accompagnée d'atteinte de la fonction rénale.

3. Les méthodes de traitement modernes, applianées immediatement après l'accident, pendent réduire l'incidence de cette complication.

4. L'hydronéphrose est frequement eliminée par résection due col vésical et la division du sphincter externe.

\section{ZUSAMMENFASSUNG}

I. Eine Hydronephrose entwickelte sich bei mehr als einem Drittel der Paraplegiker die mehrere Jahre unter Beobachtung standen.

2. Sie ist als ernste Komplikation anzurehen, wenn sie fortschreitet, und stellt eine Gefahr fuer die Nierenfunktion dar.

3. Die Anwendung moderner Behandlungsmethoden unmittelbar nach dem Unfall kann die Hauefigkeit von Hydronephrosis vermindern.

4. Die Hydronephrose kann oft eliminiert werden, wenn eine ausreichende Blasenentleerung erzielt wird. Dies kann durch Resektion des Blasenhalses und Durchschneidung des Sphincter externus erreicht werden. 


\section{REFERENCES}

Bors, E. (1957). Urol. Surv., 7, 177.

DAMANSKI, M. (I96I). Brit. F. Urol., 33I, 400.

Damanski, M., \& GibBon, N. O. K. (I956). Brit. F. Urol., 28, 24.

Hutch, J. A. (1957). F. Urol. (Baltimore), 77, 123.

Hutch, J. A. (1955). F. Urol. (Baltimore), 73, I0I9.

Hutch, J. A., \& Bunts, R. C. (1949). F. Urol. (Baltimore), 6r, 870.

Hutch, J. A., \& Bunts, R. C. (I95I). F. Urol. (Baltimore), 66, 2 I8.

LAPIDES, J. (1962). F. Urol. (Baltimore), 88, 735.

Ross, J. C., Damanski, M., \& GibBon, N. O. K. (1957). Lancet, 2, 520.

Ross, J. C., Damanski, M., \& Gibbon, N. O. K. (I958). Brit. f. Urol., 30, 204.

Ross, J. C. (1960). Encyclopaedia of Úrology, Vol. XII, p. Ioo. Berlin: Springer.

TALBOT, H. S., \& Bunts, R. C. (I949). F. Urol. (Baltimore), 6r, 870. 